\title{
Härkäpavun rikkakasvit
}

Heikki Jalli, MTT Kasvintuotannon tutkimus, 31600 Jokioinen, etunimi.sukunimi@mtt.fi

Härkäpapu on hyvä lisä kotimaisen rehuvalkuaisen tuotantoon. Se palkokasvi, joka ei tarvitse kasvaakseen paljoa lannoitetyppeä. Huolimatta pienestä typpilannoituksesta härkäpapu kasvaa rehevästi, mutta ei ole erinomainen kilpailija rikkakasveja vastaan.

Härkäpavun viljelypinta-ala suureni nopeasti ja se on nyt 10000 hehtaarin luokkaa. Viljelyinnostuksen alkaessa rikkakasvien torjumiseksi oli käytettävissä Basagran SG, bentatsoni -tehoaine, jolla ei härkäpavulla käytettynä saada tehoa linnunkaaliin, orvokkiin, peippeihin, piha- ja kietotattareeseen eikä pillikkeisiin, teho ei myöskään ole aina riittävä emäkkiin, lemmikkin, jauhosavikkaan tai ukontattareeseen. Ennen härkäpavun taimettumista käytettävä metatsaklori (Butisan S) ei tuo apua bentatsonin lisäksi paitsi hyvällä matarateholla härkäpavun rikkakasvien torjuntaan.

Kemiallisen rikkakasvien torjunnan ongelmana on härkäpavun herkkyys monille tehoaineille ja kasville sopivien tehoaineiden heikko teho useisiin rikkakasveihin.

Monipalko-hankkeessa tutkittiin herneelle hyväksyttyjen valmisteiden sopivuutta härkäpavun rikkakasvien torjuntaan kahdella koepaikalla vuosina 2009-2010. Testatut valmisteet olivat pääosin herneen ja pavun rikkakasvien torjuntaan hyväksyttyjä valmisteita.

Vuonna 2009 koejäseninä olivat Afalon-neste (linuroni) 1,5 ja 2,0 1/ha sekä Fenix (aklonifeeni) 2,0 ja 2,5 1/ha ennen härkäpavun taimettumista, Basagran SG (bentatsoni) 1,7 kg/ha ja Senkor (metributsiini) 0,4 kg/ha härkäpavun ollessa 2-4 lehtiasteella ja Fenix (aklonifeeni) 3,0 1/ha, kun härkäpapu oli 5-8 cm korkeaa. Taimille ruiskutettu Senkor samoin kuin ennen taimettumista käytetty Afalonneste vioittivat härkäpapua.

Kesällä 2010 kokeissa ei ollut mukana Senkoria eikä Afalonia. Uusina koejäseniä oli Boxer (prosulfokarbi) 4,0 1/ha, Gallery (isoksabeeni) 0,25 1/ha ja Centium (klomatsoni) 0,20 1/ha, joiden käsittelyt tehtiin ennen taimettumista

Parhaimmat rikkakasvien torjuntatulokset saatiin ennen härkäpavun taimettumista tehdyillä $\mathrm{Fe}$ nix -käsittelyillä, jotka eivät torjuneet riittävästi pillikettä ja kiertotatarta. Myös Basagranilla, ja Boxerilla saatiin hyvä teho rikkakasvien massaan (teho yli $80 \%$ ) Basagan ei torjunut pillikettä eikä Boxer jauhosavikkaa. Torjuntateho ei ollut riittävä Centiumilla, Galleryllä, Goltixilla, joista Goltix tehosi mutta muuten teho oli heikko pillikkeeseen, kiertotattareen, jauhosavikkaan ja punapeippiin.

Fenix sai Off label -hyväksynnän härkäpavun rikkakasvien torjuntaan ennen härkäpavun taimettumista huhtikuussa 2010. Aklonifeeni, bentatsoni tai metatsaklori eivät torju linnunkaalia, orvokkia, pihatatarta ja pillikkeitä, eikä teho ole riittävä emäkkiin eikä kiertotattareen. Juolavehnän ja hukkakauran torjuminen härkäpapukasvustosta tuli mahdolliseksi, kun Agil 100 EC sai huhtikuussa 2010 Off label -hyväksynnän.

\section{Asiasanat}

Herne, valkuaiskasvit, palkokasvit, kasvinsuojelu, , rikkakasvit, herbisidit, aklonifeeni, bentatsoni, isoksabeeni, klomatsoni, linuroni, metributsiini, prosulfokarbi 


\section{Johdanto}

Härkäpapu on palkokasvi, joka ei tarvitse kasvaakseen paljoa lannoitetyppeä. Huolimatta pienestä typpilannoituksesta härkäpapu kasvaa rehevästi, mutta ei ole erinomainen kilpailija rikkakasveja vastaan (Abbes et al. 2007, Grenz et al. 2005). Härkäpavun rikkakasvien torjunta on tärkeä tekijä härkäpavun sadon laadun ja satopotentiaalin hyödyntämiseksi. Rikkakasvien hallitsemiseksi tarvitaan uusia keinoja ja sopivia rikkakasvien torjunta-aineita.

Kemiallisen rikkakasvien torjunnan ongelmana on härkäpavun herkkyys monille tehoaineille (Betts \& Morrison 1979, Garcia de Arevalo 1992) ja kasville sopivien tehoaineiden heikko teho rikkakasveihin.

Härkäpavun viljelyinnostuksen alkaessa rikkakasvien torjumiseksi oli käytettävissä Basagran SG, bentatsoni -tehoaine. Bentatsonilla ei härkäpavulla käytettynä saada tehoa linnunkaaliin, orvokkiin, peippeihin, piha- ja kietotattareeseen eikä pillikkeisiin, teho ei myöskään ole aina riittävä emäkkiin, lemmikkin, jauhosavikkaan tai ukontattareeseen. Toinen mahdollinen valmiste, ennen härkäpavun taimettumista käytettävä metatsaklori (Butisan S) ei tuo apua bentatsonin lisäksi paitsi paremmalla matarateholla härkäpavun rikkakasvien torjuntaan. Rikkakasvien hallitsemiseksi tarvitaan uusia keinoja ja sopivia rikkakasvien torjunta-aineita.

\section{Aineisto ja menetelmät}

Monipalko-hankkeessa tutkittiin herneelle hyväksyttyjen valmisteiden sopivuutta härkäpavun rikkakasvien torjuntaan kahdella koepaikalla (Jokioisilla ja Koskella Tl) vuosina 2009-2010.

Testatut valmisteet olivat herneen ja pavun rikkakasvien torjuntaan hyväksyttyjä valmisteita. Basagran SG (1,7 kg/ha) ja Senkor (0,4 kg/ha) härkäpavun ollessa 2-4 lehtiasteella, Afalon (1,5 ja 2,0 1/ha) sekä Fenix (2,0, 2,5 1/ha) ennen härkäpavun taimettumista ja Fenix 3,0 1/ha, kun härkäpapu oli 5$8 \mathrm{~cm}$ korkeaa.

Kesällä 2010 kokeissa ei ollut Senkoria, eikä Afalonia, jonka markkinoilla pysymistä epäiltiin. Uusina koejäseniä Boxer (4,0 1/ha), Gallery $(0,25$ l/ha) ja Centium $(0,20$ l/ha), joiden käsittelyt tehtiin ennen taimettumista. Basagran SG 1,7 1/ha kun härkäpavussa 2-4 lehteä, ja Fenix 3,0 1/ha härkäpavun ollessa 5-8 cm korkeaa.

\section{Tulokset ja tulosten tarkastelu}

Kasvukaudella 2009 härkäpavun taimettumisen jälkeen käytetyt Senkor $(0,4$ kg/ha) Kuva 1. ja Fenix (3,0 1/ha) Kuva 2.) vioittivat kasvia pahoin. Jokioisilla härkäpavun taimettumisen jälkeen käytetyt Afalon (Kuva 3) ja Fenix vioittivat kasvia (Kuva 4.), Kosken kentällä vain Fenix (ei esitetty).

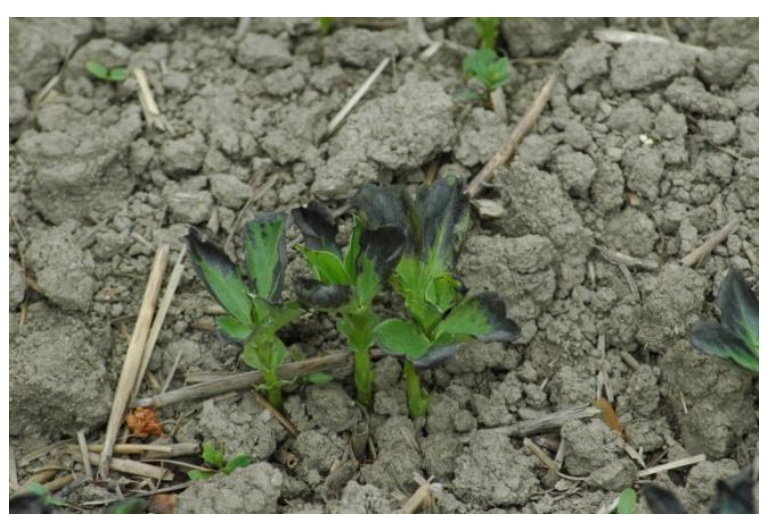

Kuva 1. Senkor 0,4 kg/ha 


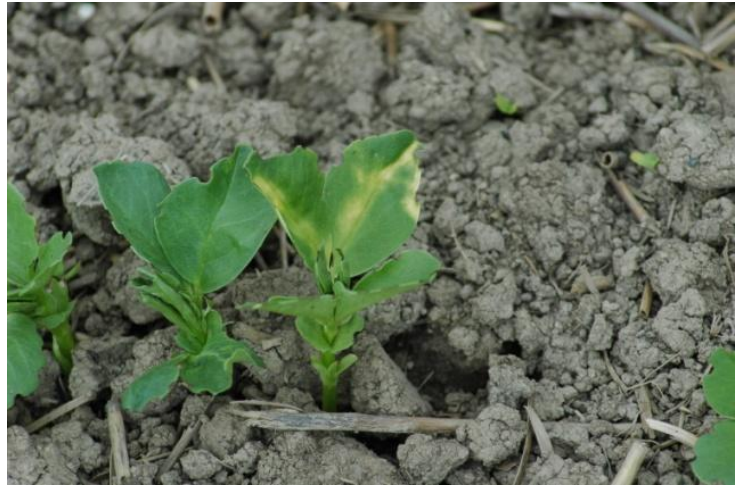

Kuva 2. Fenix 3,0 1/ha vioitus

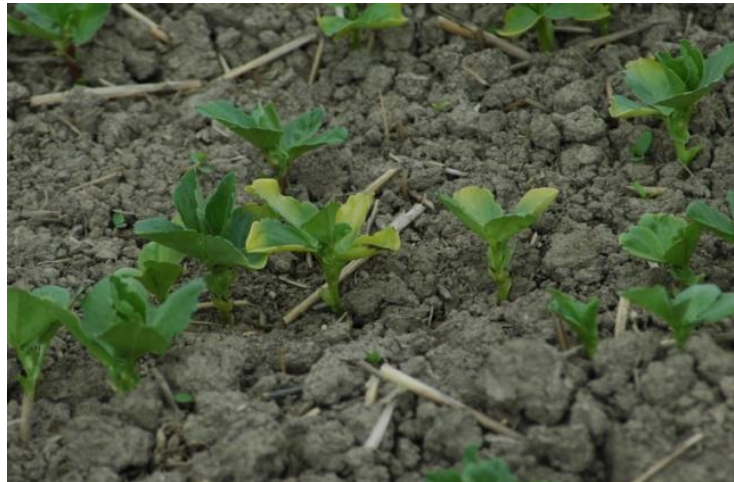

Kuva 3. Afalon 2.0 1/ha

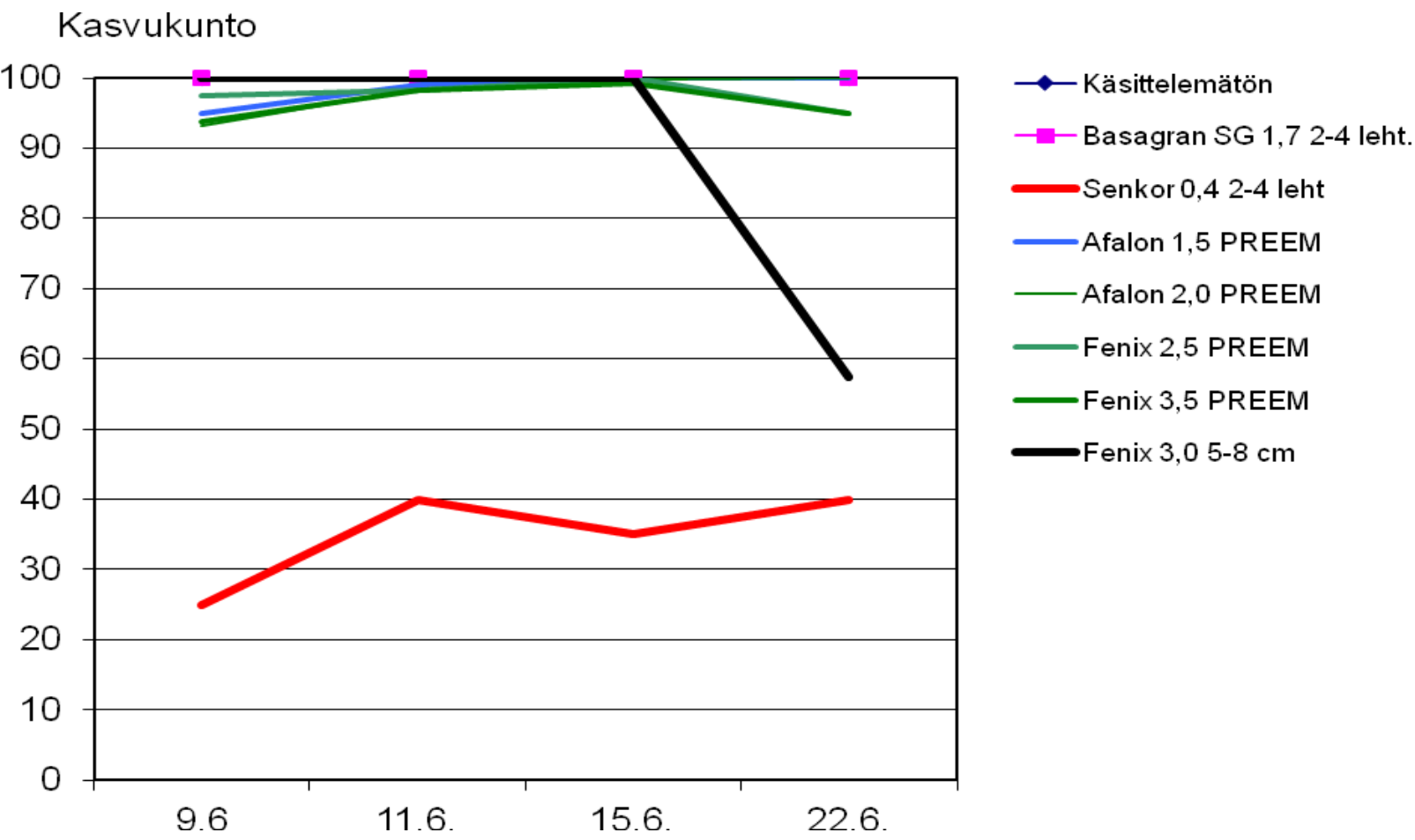

Kuva 4. Etenkin härkäpavun taimille ruiskutetut Senkor ja Fenix vioittivat härkäpapua Jokioisilla 2009.

Kesällä 2009 rikkakasveja torjui parhaiten Fenix 3,5 1/ha ennen härkäpavun taimettumista käytettynä. Herbisikäsittelyjen vioitukset näkyvät häkäpavun painoissa (Kuva 5.) 


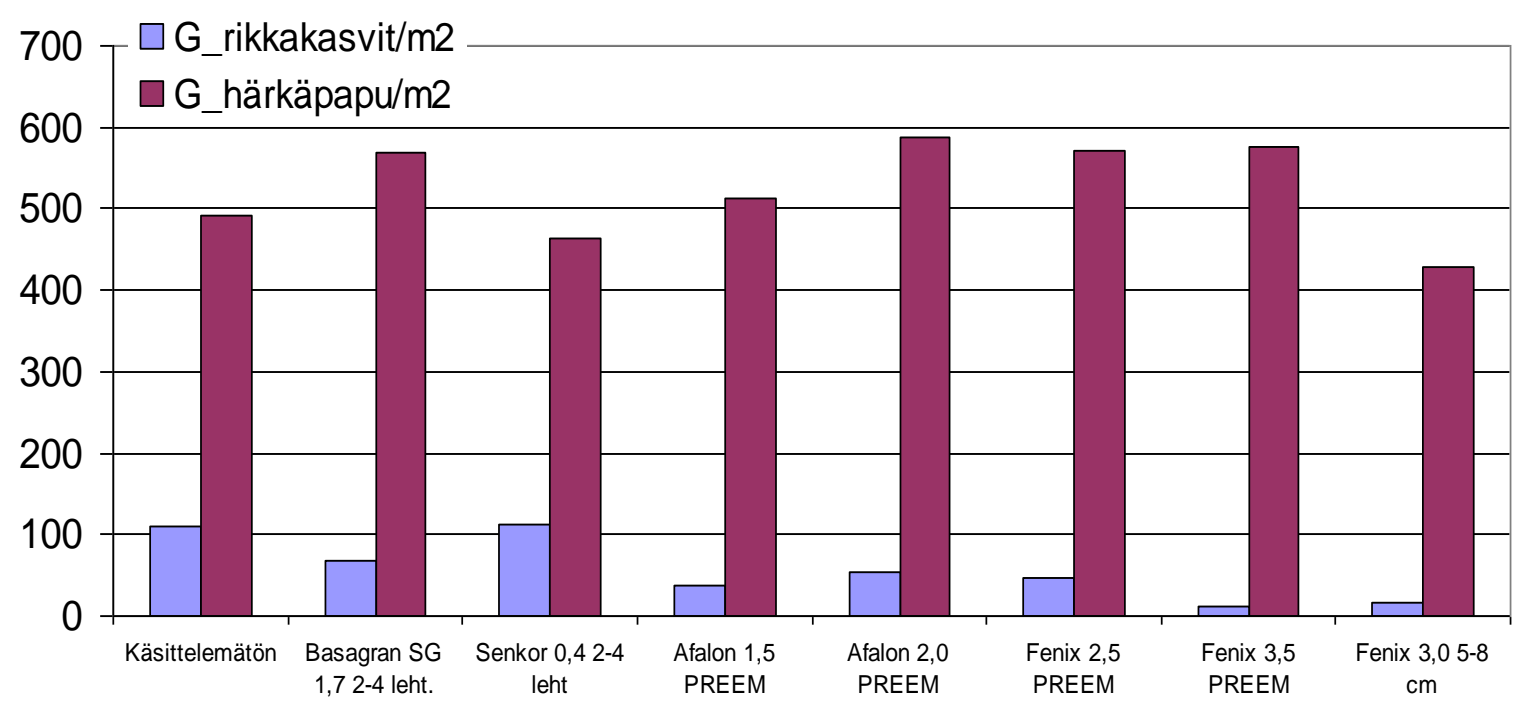

Kuva 5. Rikkakasvien ja härkäpavun massa 2009 kahdessa kokessa toinen Jokioisilla toinen Koskella $\mathrm{Tl}$

Kesällä 2010 kokeissa ei ollut Senkoria, joka vioitti härkäpapua eikä Afalonia, jonka markkinoilla pysymistä epäiltiin. Uusina koejäseniä Boxer (4,0 1/ha), Gallery $(0,25$ 1/ha) ja Centium $(0,20$ 1/ha), joiden käsittelyt tehtiin ennen taimettumista. Basagran SG 1,7 1/ha kun härkäpavussa 2-4 lehteä, ja Fenix 3,0 1/ha härkäpavun ollessa 5-8 cm korkeaa.

Senkorin ja Afalonin poisjäännin jälkeen vioitukset olivat paljon pienepiä kun edellisenä vuonna, vain taimettumisen jälkeen ruiskutettu Fenix vioitti (Kuva 6.).
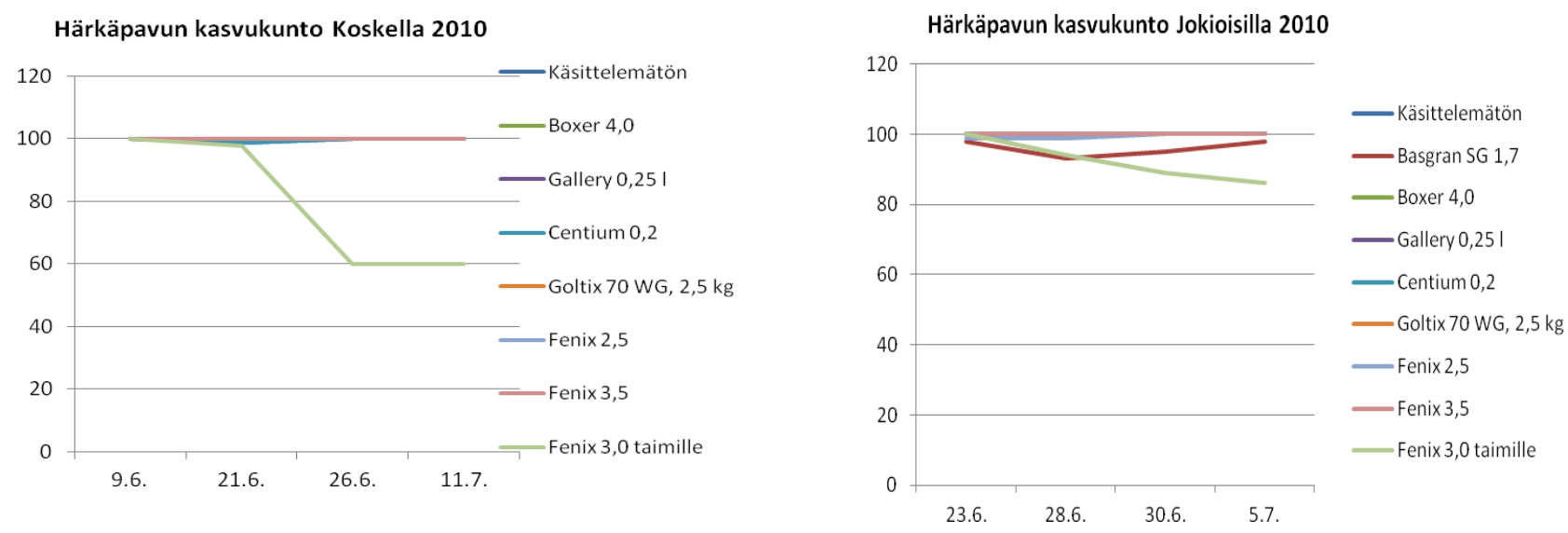

Kuva 6. 2010 taimelle annettu Fenix vioitti härkäpapua eri voimakkuudella(vaaleanvuhreä viiva) 


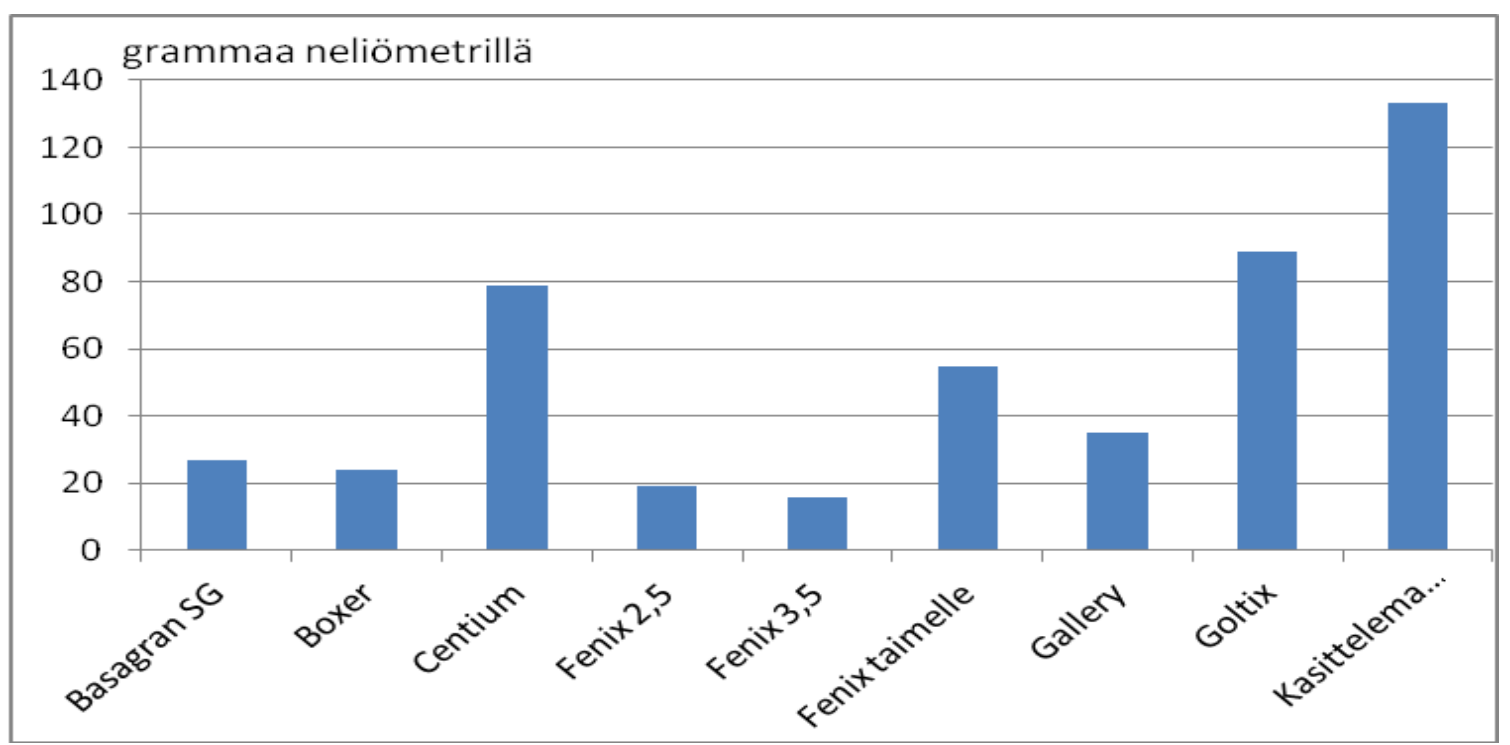

Kuva 7. Härkäpavulla testattujen herbisidien teho kahdessa kokeessa syksyllä 2010.

Parhaimmat rikkakasvien torjuntatulokset saatiin ennen härkäpavun taimettumista tehdyillä Fenix -käsittelyillä. Myös Basagranilla ja Boxerilla saatiin hyvä teho, yli $80 \%$. Teho ei ollut riittävä Galleryllä, Goltixilla ja Centiumilla, eikä taimettumisen jälkeen käytetyllä Fenixillä. (Kuva 7) Basagan ei torjunut pillikettä. Aklonifeenin tehoalue poikkeaa bentatsonin rikkakasvitehospektristä. Kummallakaan tehoaineella ei härkäpavulla käytettynä saada tehoa linnunkaaliin, orvokkiin, pihatattareeseen ja pillikkeisiin, eikä teho ole riittävä emäkkiin, kiertotattareeseen, peippeihin ja jauhosavikkaan.

Boxerilla saatiin hyvä teho rikkakasvien massaan (teho yli $80 \%$ ) se ei torjunut jauhosavikkaa. Torjuntateho ei ollut riittävä Centiumilla, Galleryllä ja Goltixilla, joista Goltix tehosi pillikkeeseen , mutta muuten teho oli heikko kiertotattareen, jauhosavikkaan ja punapeippiin. Myös taimettumisen jälkeen käytetyn Fenixin teho rikkakasvimassoihin oli 50 prosentin luokkaa.

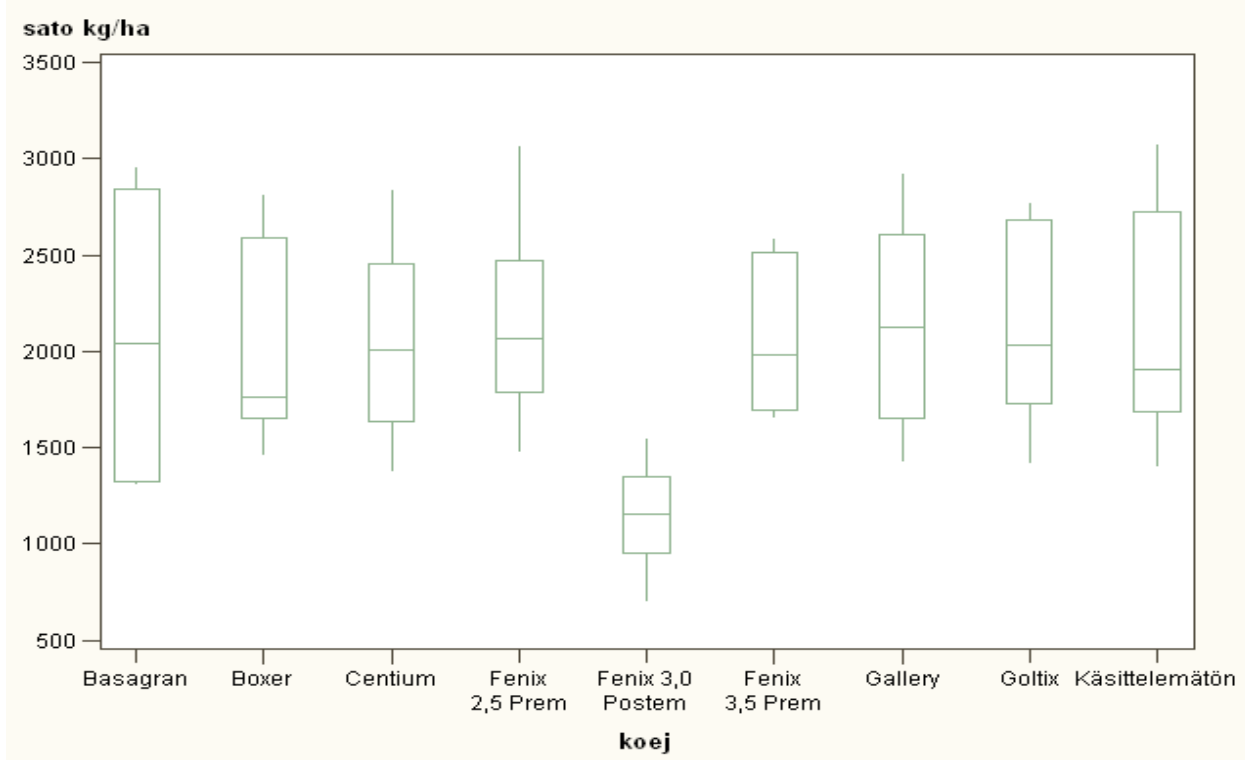

Kuva 8. Härkäpavun sato 2010 kahdessa kokeessa.

Härkäpapu kärsi keväällä 2010 kuivuudesta, ja sato jäi pieneksi (Kuva 8.) 


\section{Johtopäätökset}

Aklonifeeni (Fenix) sopii härkäpavun rikkakasvien torjuntaan ennen härkäpavun taimettumista, mutta ei viljelykasvin taimille ruiskutettuna, kuten herneellä. Fenix sai Off label - hyväksynnän härkäpavun rikkakasvien torjuntaan ennen härkäpavun taimettumista huhtikuussa 2010.

Juolavehnän ja hukkakauran torjuminen tuli mahdolliseksi, kun Agil 100 EC sai Off label - hyväksynnän juolavehnän ja hukkakauran torjuntaan härkäpavusta. Tähänastiset Off label -hyväksynnät tuovat apua härkäpavun rikkakasvien torjuntaan, vaikka rikkakasvilajiston koostuessa pillikkeestä tai kiertotattaresta voi herbisidien teho jäädä riittämättömäksi.

\section{Kirjallisuus}

Abbes, Z., Kharrt, M., Delavault,P., Simier, P \& Chaibi, E. 2007. Field evaluation of the resistance of some faba bean (Vicia faba L.) genotypes to the parasitic weed Orobanche foetida Poiret. Crop Protection. 12: 1777-1784

Betts, M., F. \& Morrison I, N. 1979. Fall and spring applications of trifluralin and metribitzin in fababeans (Vicia faba). Weed Science. 6: 61-64.

Garcia de Arevalo R. C., Sanchez, M. A., Algarra, P.J.H., Lusarreta, C. A. \& Veyra, C.B. 1992. Chemical control of annual weeds in field beans (Vicia faba) in central Spain. Weed science. 40: 96100.

Grenz, J. H., Manschadi, A. M., Uygur, F.N. \& Sauerborn, J. 2005. Effects of environment and sowing date on the competition between faba bean (Vicia faba) and the parasitic weed Orobanche crenata Field Crops Research. 93: 300-313. 